\title{
Effects on Consumers' Subjective Understanding and Liking of Front-of-Pack Nutrition Labels: A Study on Slovenian and Dutch Consumers
}

\author{
Angelo Baccelloni ${ }^{1, *}$, Andrea Giambarresi ${ }^{2}$ and Marco Francesco Mazzù $^{3}$ (D) \\ 1 Department of Communication and Social Research, Sapienza University of Rome, Via Salaria, \\ 00198 Roma, Italy \\ 2 Department of Business and Management, LUISS Guido Carli University, Viale Romania, 00197 Rome, Italy; \\ agiambarresi@luiss.it \\ 3 Luiss Business School, Via Nomentana, 00162 Roma, Italy; mmazzu@luiss.it \\ * Correspondence: angelo.baccelloni@uniroma1.it
}

check for updates

Citation: Baccelloni, A.; Giambarresi,

A.; Mazzù, M.F. Effects on

Consumers' Subjective

Understanding and Liking of

Front-of-Pack Nutrition Labels: A Study on Slovenian and Dutch

Consumers. Foods 2021, 10, 2958.

https://doi.org/10.3390/

foods10122958

Academic Editor: Rossella Di Monaco

Received: 31 October 2021

Accepted: 26 November 2021

Published: 1 December 2021

Publisher's Note: MDPI stays neutral with regard to jurisdictional claims in published maps and institutional affiliations.

Copyright: (c) 2021 by the authors. Licensee MDPI, Basel, Switzerland. This article is an open access article distributed under the terms and conditions of the Creative Commons Attribution (CC BY) license (https:/ creativecommons.org/licenses/by/ $4.0 /)$

\begin{abstract}
In the context of the ongoing debate on front-of-pack labels (FOPL), extant research highlights a lack of clear indications on which label is most effective in increasing consumers' knowledge of food nutritional quality, and in favoring informed food choices. In this study, we have compared the effects of two different labels, one nutrient-specific label (i.e., NutrInform Battery) and one summary label (i.e., Nutri-Score), in terms of consumers" "subjective understanding" and "liking". Our work advances prior research on FOPL performance by focusing on two different countrieswhich have different socio-political contexts and which, from previous studies, present limited evidence on the topic-Slovenia, currently utilizing the Protective Food logo, and the Netherlands, who has recently adopted the Nutri-Score. The study also confirms, in line with previous research, a higher effectiveness of the nutrient-specific label, NutrInform Battery, on all analyzed dimensions in tested countries, when compared to the summary label, Nutri-Score.
\end{abstract}

Keywords: front-of-pack nutritional label; Nutri-Score; NutrInform Battery; subjective understanding; liking; overweight; obesity; Slovenia; Netherlands

\section{Introduction}

In the last few years, the phenomena of overweight and obesity have emerged as some of the most serious global health problems, with consequences on several noncommunicable diseases [1]. Their rate has nearly tripled since 1975: recent predictions forecast that $50 \%$ of global citizens will be overweight by 2030 [2]. In 2016, 1.9 billion people over 18 were considered overweight, whereas in the youngest part of the population, ranging from 5 to 19 years old, 340 million of people were found to be overweight or obese [1]. In response to this growing issue, governmental bodies (e.g., EU, WHO) have, since 2006, undertaken actions to support consumers in making informed food choices, with the goal of decreasing obesity, and its direct and indirect costs on public health systems.

The COVID-19 pandemic has worsened the situation for the obese population. The risk of being hospitalized with COVID-19, for people who are overweight or obese, is increased by $113 \%$, the risk of being admitted to the intensive care unit by $74 \%$, and the risk of dying by $48 \%$ [3]. Public Health England has registered similar numbers regarding mortality reporting an increase of $90 \%$ of the risk of death from COVID-19 for individuals with BMI rate greater than 40 [3]. Furthermore, a World Obesity Federation report released on 4 March 2021 showed additional trends, noting that COVID-19 mortality rates were ten times higher in countries in which more than half of the population is obese [3].

In line with the World Health Organization (WHO), these forecasts can be avoided from happening through an integrated set of actions at different levels: individual; industrial; and governmental [1]. 
In this context, the EU introduced specific regulations (e.g., 1169/2011) for the establishment of food front-of-pack labels (FOP labels or FOPLs) that can support consumers in making informed food choices, and the WHO [1] identified FOPLs as an effective tool to limit the increase of diet-related diseases.

As a result, numerous member states have begun to develop their own front-of-pack labels (Table 1) [4], such as the United Kingdom in 2013 (Multiple Traffic Light), France in 2017 (Nutri-Score), and Italy in 2019 (NutrInform Battery). The introduction of these FOPLs has led to a debate on which label should be adopted for the whole European Union [5]. These labels follow different-and complementary-approaches, and can be classified, according to the recent EU taxonomy (Table 1), into nutrient-specific or summary labels [6]. Nutrient-specific labels present detailed numerical data regarding the nutritional values of foods, specifically on energy value, fat, saturated fat, sugar, and salt, and also through percentages and the usage of colors and symbols. On the other hand, summary labels provide an evaluation of the general healthiness of the product, often through algorithms.

Table 1. European taxonomy on front-of-pack labels and FOPL definition by WHO.

\begin{tabular}{|c|c|c|}
\hline \multicolumn{3}{|c|}{ Front of Pack Label-Definiton } \\
\hline $\begin{array}{l}\text { Front-of-pack labelling (FOPL) refers to } \\
\text { nutrition labelling systems that: a) are } \\
\text { presented on the front of food packages } \\
\text { (in the principal field of vision) and can } \\
\text { be applied across the packaged retail } \\
\text { food supply; b) comprise an } \\
\text { underpinning nutrient profile model that } \\
\text { considers the overall nutrition }\end{array}$ & Nutrient-Specific Labels & $\begin{array}{l}\text { - Numerical labels (e.g., NutrInform Battery). } \\
\text { Non-interpretative (non evaluative) label, providing } \\
\text { numerical information on the content of four nutrients } \\
\text { (fat, saturates, sugars, salt) and on the energy value, as } \\
\text { well as on how much this represents as a percentage of } \\
\text { the daily reference intake } \\
\text { - Colour-Coded Labels (e.g., Multiple Traffic Lights). } \\
\text { The label provides numerical information on the } \\
\text { content of four nutrients (fat, saturates, sugars, salt) } \\
\text { and on energy value, as well as on how much this } \\
\text { represents as a percentage of the daily reference intake. } \\
\text { Colors are used to classify those nutrients as "low } \\
\text { (green), "medium" (amber) or "high" (red) }\end{array}$ \\
\hline & Summary Labels & $\begin{array}{l}\text { - Endorsement Logos (e.g., Keyhole logo). The label } \\
\text { provides a synthetic appreciation of a product's } \\
\text { overall nutritional value through a positive } \\
\text { (endorsement) logo that is applied only to foods that } \\
\text { comply with nutritional criteria } \\
\text { - Graded Indicators (e.g., Nutri-Score) The label } \\
\text { provides a synthetic appreciation of a product's } \\
\text { overall nutritional value through a "graded indicator" } \\
\text { that provides graded information on the nutritional } \\
\text { quality of foods that is applied on all food products }\end{array}$ \\
\hline
\end{tabular}

This study aims at further contributing to the European discussion on label adoption, comparing the performance of different FOPLs in two countries with limited evidence on the impact of FOPL on consumers, with specific attention to the pre-usage phase of subjective understanding and liking.

\section{Extant Literature and Research Objectives}

Grunert and Wills [7] modelled the consumer decision-making process regarding food, and outlined the five stages that lead to the use of a product: exposure; perception; understanding; liking; and use.

Among the factors that influence the usage phase, the two different elements that form understanding - objective and subjective- have been deeply investigated by the recent FOPL literature.

Objective understanding is defined whether the meaning attributed by the consumer to the label is in line with the meaning intended by the sender of the label (i.e., if the 
consumers have understood what the sender wanted to communicate), whereas subjective understanding is the meaning that the consumer obtains from the perception of the information present on the labels (i.e., what consumers believe they understand about nutrition factors relevant to their nutrition knowledge).

Recent studies (Table 2) compared the performance of different FOPLs along the two dimensions of understanding, and produced on one side, coherent results within each research stream, and on the other side, contrasting evidences and outputs between objective and subjective understanding [8]. Specifically, summary labels have been shown to be more effective in supporting objective understanding, also due to the use of color, which attracts consumers' attention, and facilitates decision-making in time-constrained situations [9-12]. Recent research [13] performed in Slovenia confirmed the higher ability of the Nutri-Score to differentiate food products on the basis of composition. A recent study conducted in a Dutch supermarket by Van den Akker et al. [14] on FOPLs' effectiveness in guiding consumer choices reported that the Nutri-Score can help consumers toward healthier choices, while not increasing the intended serving sizes.

Table 2. Prior research on subjective and objective understanding.

\begin{tabular}{cccc}
\hline & Author & Tested Country & Period of Time \\
\hline $\begin{array}{c}\text { Objective } \\
\text { Understanding }\end{array}$ & Ducrot et al. & France & 2015 \\
\hline & Egnel et al. & $\begin{array}{c}\text { Multiple countries (Denamrk, France, } \\
\text { Germany, Spain, UK, United States) }\end{array}$ & 2018 \\
\hline Egnel et al. & Netherlands & 2018 \\
\hline $\begin{array}{c}\text { Subjective } \\
\text { Understanding }\end{array}$ & Mazzù et al. & $\begin{array}{c}\text { Belgium, Bulgaria, Denmaark, France, } \\
\text { Germany, Italy, Netherlands, Poland, } \\
\text { Portougal, Spain, Switzerland, United } \\
\text { Kingdom) }\end{array}$ & 2020 \\
\hline & Mazzù et al. & $\begin{array}{c}\text { Italy, France, Germany, Spain, } \\
\text { Portougal, Greece, Romania }\end{array}$ & 2020 \\
\hline & Mazzù et al. & Poland \\
\hline
\end{tabular}

Studies on subjective understanding have also shown that consumers are able to better understand nutritional values when using a nutrient-specific label, as this kind provides more complete and specific information [15-17].

Our research tests two labels that are at the extremes of the EU taxonomy to gain evidence on opposite approaches to FOP labelling: the Nutri-Score, as the most representative summary label at the EU level, and the recently introduced NutrInform Battery. Countries have been selected complementing research already fielded on similar topics [7,17], and because they represent very different socio-political contexts.

The Protective Food Logo was introduced in Slovenia in 1992, with the aim to support consumers in their decision-making process toward healthier choices, and to encourage a rework on food formulations [18]. The logo presents the specific nutrient criteria that a product has to achieve to be able to carry the symbol; in this way, the consumer is implicitly told that the product in question has met specific requirements [19]. The Protective Food Logo is based on the combination of food-traffic-light thresholds and regulatory criteria for certain nutritional and health claims - the symbol is supported by a specific claim, which presents the benefits of the product [18]. This symbol can now be found on about $2 \%$ of the products on the market, in a context where less than half of the Slovenian population (42\%) does not pay attention to food labels [18]. A study from 2016 made by Miklavec et al. [20] on the Slovenian Protective Food Logo reported that $78 \%$ of the participants had previously seen the symbol, and $64 \%$ of them declared to be familiar with it. These results 
show an increase in familiarity of the symbol among Slovenian adults: the familiarity rate has increased from $40 \%$ in 2000 to $64 \%$ in 2016 [20]. This data shows an increased attention of the Slovenian population towards their food intake.

A study by Kupirovic et al. [18] focuses on the problem of scenarios presenting conflictual information: food can be considered healthy by the symbol, for example the Protective Food Logo, but unhealthy by scoring labels such as the Nutri-Score.

Furthermore, the Nutri-Score has demonstrated to have some blind spots given the fact that some ingredients (e.g., synthetic ingredients) are not taken into account while the main message is that the product should be consumed in reasonable quantities [21]. In a cross-country study regarding consumers' understanding of FOPLs, Gregori et al. [22] reported that front-of-pack labels enhance comprehension, understanding, and interpretation of nutritional information, enhancing consumer comprehension and comfort level with such information. Furthermore, the research concluded that FOP labels encourage food manufacturers to reformulate their products, and develop new products with a healthier composition. Other studies [23] have shown that in Slovenia, the willingness to pay for products with a front-of-pack label was higher than the average of the other European countries considered. In 2019, however, the adult population in Slovenia was $19.9 \%$ obese, and $38.2 \%$ was overweight [24], with a subsequent overall and childhood obesity risk.

The Netherlands recently adopted the Nutri-Score while continuing to analyse the underlying algorithm given the fact that it's scores are not very consistent with Dutch dietary guidelines [25]. In 2020,36.8\% of the population was overweight, and $14.2 \%$ of the population was obese, increasing since 2002, where the obesity rate was $10.4 \%$, and the overweight rate was 35.3\% [24]. Due to the growing problem of obesity, before the Nutri-Score, the Netherlands adopted the voluntary Dutch Choices label, to indicate a product's level of healthiness. The Choices label was developed in two different variants: (a) a green logo indicating which are the healthy choices within basic product categories; and (b) a blue logo indicating which are the healthier choices within non-basic product categories [19]. The results of research conducted by Vyth et al. [26] reported that exposure to the Dutch Choices label has increased significantly during recent years, and has received different responses according to the customer category. Older, obese respondents reported more need for the logo than younger, normal-weight individuals. Women evaluated the logo to be more attractive and credible than men. Further qualitative analysis has shown that: (a) if the government and scientific authorities were to support the logo, its credibility would improve; (b) older respondents said that, for them, the logo is needed because of health concerns; and (c) consumers who are interested in health use the logo. Vyth et al. in 2010 [27], in research on the purchasing behaviour of the Dutch population in grocery shops, reported that both participants who are careful about their weight and familiar with looking at nutrition information on food packages would chose products with the Choice label. Van Herpen et al. [28], who studied the role of familiarity in the evaluation of FOPLs in the Netherlands and in the United Kingdom, highlighted that the level of familiarity with the label influences self-reported evaluations, usage intentions, and healthful choices. Smed et al. [29], who carried out a study in the Netherlands using household purchasing data, reported a positive effect of labelling for the majority of products. Furthermore, products with the voluntary Dutch Choices label (which indicates that a product is a "healthy" choice) have increased the market share after displaying the scheme [29]. A study by Egnell et al. [30] compared different FOP labels (Health Star Rating, Multiple Traffic Light, Reference Intake, Warning Symbols), and tested their impact on the objective understanding of Dutch consumers: the Nutri-Score was found to have the best performance in helping consumers sort foods on the basis of their nutritional quality. Research conducted by Jewell [19] comparing the performance of FOP labels on the market highlighted that Dutch people were not able to differentiate their Choice Logo with the Green Endorsement Logo: moreover, not all of the manufacturers have participated in the scheme, causing potential confusion on whether the non-appearance of the logo implies product un-healthiness or not. Those results show the need for a label that had greater 
support from scientific and governmental authorities, and for this reason, in 2021, the Netherlands chose to adopt the summary label Nutri-Score.

In this context, the study has the goal of providing additional evidence concerning the relative effectiveness of two labels at the extreme of the EU taxonomy-NutrInform Battery and Nutri-Score-with the purpose of increasing consumers' awareness, and helping consumers make healthier choices.

Based on results highlighted in previous research [15-17], we expect that, with respect to the three sub-dimensions of "subjective understanding" and to "liking", a nutrientspecific label (NutrInform Battery) will perform better than a summary label (the NutriScore) in both tested countries, Slovenia and the Netherlands.

In particular, we hypothesize the following by considering the three sub-dimensions of subjective understanding (comprehensibility, help-to-shop, complexity):

Hypothesis 1a (H1a). The NutrInform Battery (vs. the Nutri-Score) has a higher impact on the labels' comprehensibility in Slovenia.

Hypothesis $\mathbf{1 b} \mathbf{~ ( H 1 b ) . ~ T h e ~ N u t r I n f o r m ~ B a t t e r y ~ ( v s . ~ t h e ~ N u t r i - S c o r e ) ~ h a s ~ a ~ h i g h e r ~ i m p a c t ~ o n ~ t h e ~}$ labels' comprehensibility in the Netherlands.

Hypothesis 1c (H1c). The NutrInform Battery (vs. the Nutri-Score) has a higher impact on the labels' help to shop in Slovenia.

Hypothesis 1d (H1d). The NutrInform Battery (vs. the Nutri-Score) has a higher impact on the labels' help to shop in the Netherlands.

Hypothesis 1e (H1e). The NutrInform Battery (vs. the Nutri-Score) has a higher impact on the labels' complexity in Slovenia.

Hypothesis $1 \mathbf{f}$ (H1f). The NutrInform Battery (vs. the Nutri-Score) has a higher impact on the labels' complexity in the Netherlands.

Furthermore, regarding liking, we have hypothesized that:

Hypothesis 2a (H2a). The NutrInform Battery (vs. the Nutri-Score) has a higher impact on the labels' liking in Slovenia.

Hypothesis $\mathbf{2 b}$ (H2b). The NutrInform Battery (vs. the Nutri-Score) has a higher impact on the labels' liking in the Netherlands.

\section{Materials and Methods}

As stimuli, in the present research, we utilized NutrInform Battery and Nutri-Score. The two labels were chosen because they represent different approaches to front-of-pack labelling, and have a different degree of presence in the extant literature.

A between-subjects design has been utilized for the research, with the two different FOPL conditions serving as the basis for the study. Each condition was placed on mock packages of the same types of food categories, to investigate the impact of the two alternatives on four dependent variables, i.e., the three sub-dimensions of subjective understanding (comprehensibility, help-to-shop, and complexity), plus liking. Mock products have been used in order to avoid the effects of brand exposure that could mislead consumers [10]. Participants were randomly assigned to the different tested conditions. The questionnaire was structured on the Qualtrics platform, translated into the original language with the support of a professional translator, and delivered via Prolific Academic, an on-demand, self-service data collection that supports the recruitment of high-quality research participants. The questionnaire opened with the collection of socio-demographic 
information, followed by the core part, in which respondents were asked to provide an assessment of all the sub-dimensions of subjective understanding, and of liking.

A description of the socio-demographics of each sample is provided in the table below (Table 3)

Table 3. Details of sample size by socio-demographic information.

\begin{tabular}{|c|c|c|}
\hline Variables & Slovenia & The Netherlands \\
\hline \multicolumn{3}{|l|}{ Age } \\
\hline $18-24$ & $42.9 \%$ & $8.5 \%$ \\
\hline $25-34$ & $42.8 \%$ & $41.9 \%$ \\
\hline $35-44$ & $12.3 \%$ & $36.7 \%$ \\
\hline $45-54$ & $2 \%$ & $12.1 \%$ \\
\hline $55+$ & $0 \%$ & $0.8 \%$ \\
\hline \multicolumn{3}{|l|}{ Education } \\
\hline Lower than diploma & $4 \%$ & $3.6 \%$ \\
\hline Diploma & $55 \%$ & $27 \%$ \\
\hline Bachelor Degree & $15 \%$ & $27.8 \%$ \\
\hline Master Degree & $18 \%$ & $34.7 \%$ \\
\hline $\mathrm{PhD}$ & $8 \%$ & $6.9 \%$ \\
\hline \multicolumn{3}{|l|}{ Gender } \\
\hline Male & $60 \%$ & $50 \%$ \\
\hline Female & $40 \%$ & $50 \%$ \\
\hline \multicolumn{3}{|l|}{ Income } \\
\hline$<20 \mathrm{k}$ & $74 \%$ & $23 \%$ \\
\hline 20-40k & $24.4 \%$ & $38.7 \%$ \\
\hline $41-60 \mathrm{k}$ & $1 \%$ & $23.4 \%$ \\
\hline $61-80 \mathrm{k}$ & $0 \%$ & $9.3 \%$ \\
\hline $81-100 k$ & $0 \%$ & $4.4 \%$ \\
\hline$>100 \mathrm{k}$ & $0.6 \%$ & $1.2 \%$ \\
\hline \multicolumn{3}{|l|}{ Profession } \\
\hline Student & $40 \%$ & $0.8 \%$ \\
\hline Unemployed & $17 \%$ & $13.7 \%$ \\
\hline Part-time & $5 \%$ & $21 \%$ \\
\hline Full-time & $31 \%$ & $50.4 \%$ \\
\hline Self-employed & $6 \%$ & $10.5 \%$ \\
\hline Housewife & $1 \%$ & $1.6 \%$ \\
\hline Cannot work & $0 \%$ & $2 \%$ \\
\hline
\end{tabular}

The items in each sub-dimensions (Table 4) were derived from previous research [31,32], and were consistent with recent past research on subjective understanding [15-17].

- Comprehensibility: "I feel well informed by the food label"; "This label is believable and trustworthy"; and "This label is easy to interpret". We used a 7-point Likert scale from $1=$ Completely Disagree to $7=$ Completely Agree.

- Help-to-shop: "This label helps me understand the product composition"; "This label helps me to understand different nutritional values"; and "This label makes it easier to choose food". We used a 7-point Likert scale from $1=$ Completely Disagree to 7 = Completely Agree.

- Complexity: "The food label is rather extensive"; and "Using this food label to choose food is better than just relying on my own knowledge about what is in them". We used a 7-point Likert scale from $1=$ Completely Disagree to $7=$ Completely Agree.

- Liking: "How do you evaluate the label?" Respondents expressed their opinion answering to the following scales: "bad/good"; "unfavourable/favourable"; and "negative/positive". $(1=\mathrm{Bad}, 7=$ Good; 1 = Unfavorable, $7=$ Favorable; $1=$ Negative, 7 = Positive). It is important to notice that the item utilised to measure the third subdimension of subjective understanding, complexity, does measure a reduction of the perceived complexity by the consumer. 
Table 4. Tested Scales.

\begin{tabular}{|c|c|c|}
\hline & Scale Item & Reference \\
\hline \multirow[t]{4}{*}{ Comprehensibility } & & Moser et al. 2010 \\
\hline & I feel well informed by the food label & \\
\hline & This label is believable and trustworthy & \\
\hline & This label is easy to interpret & \\
\hline \multirow[t]{4}{*}{ Help-to-shop } & & Moser et al. 2010 \\
\hline & $\begin{array}{l}\text { This label helps me to understand the product } \\
\text { composition }\end{array}$ & \\
\hline & $\begin{array}{c}\text { This label helps me to understand different } \\
\text { nutritional values }\end{array}$ & \\
\hline & This label makes it easier to chose food & \\
\hline \multirow[t]{2}{*}{ Complexity } & & Moser et al. 2010 \\
\hline & $\begin{array}{l}\text { The food label is rather extensive } \\
\text { Using this food label to choose food is better } \\
\text { than just relying on my own knowledge about } \\
\text { what is in them }\end{array}$ & \\
\hline \multirow[t]{2}{*}{ Liking } & & $\begin{array}{c}\text { Allen and } \\
\text { Janiszewski, } 1989\end{array}$ \\
\hline & $\begin{array}{l}\text { How do you evaluate the label } \\
\text { Bad/Good } \\
\text { Unfavourable/Favourable } \\
\text { Negative/Positive }\end{array}$ & \\
\hline
\end{tabular}

We utilized three covariates-age, education, and income level—in line with past research. Extant studies highlight that lower income levels lead to a preference for evaluative/directive labels, and to lower label use $[9,33,34]$. The level of education influences the understanding of the label, with evidences of the fact that nutrient-specific labels have lower levels of understanding for respondents with a lower level of education $[11,14,34,35]$. Finally, prior studies showed how age impacts the dependent variables, with children having a preference for evaluative labels [35], whereas older people are less likely to collect additional information from FOP labels at all [36].

\section{Results}

We compared participants' evaluations of the different conditions using Students' $t$ tests. IBM SPSS Statistics 25 software (Armonk, NY, USA) was used to perform the analyses, only on data from participants who had completed the questionnaire appropriately, and that had passed the attention check.

We first assessed reliability by calculating the Cronbach's alpha registered in both countries by the tested items (Table 5), and then we calculated the mean of the items for the dimensions of comprehensibility, help-to-shop, complexity, and liking.

Table 5. Scales reliability (Cronbach's alpha) by country.

\begin{tabular}{ccc}
\hline & The Netherlands & Slovenia \\
\hline Comprehensibility & 0.71 & 0.81 \\
Help-to-Shop & 0.81 & 0.79 \\
Complexity & 0.77 & 0.65 \\
Liking & 0.89 & 0.83 \\
\hline
\end{tabular}

The results reported a similar performance in both in Slovenia and the Netherlands (Table 6). The product with the NutrInform Battery registered a better performance than the one with the Nutri-Score in all the three sub-dimensions of subjective understanding, comprehensibility, help-to-shop, and complexity. Regarding liking, we registered a different performance of the two FOPLs: though in Slovenia, the NutrInform Battery significantly 
outscored the Nutri-Score, in the Netherlands, the differences between the means reported by the two labels were not statistically significant.

Table 6. Mean scores by country (healthy and less healthy) on comprehensibility, help-to-shop, complexity, liking, for Nutri-Score and NutrInform Battery adjusted for age, education, income status.

\begin{tabular}{|c|c|c|c|c|c|c|c|c|}
\hline & \multicolumn{2}{|c|}{ NutrInform Battery } & \multicolumn{2}{|c|}{ Nutri-Score } & \multicolumn{2}{|c|}{ t-Test Statistics } & \multicolumn{2}{|c|}{$p$ Value } \\
\hline & Slovenia & Netherland & Slovenia & Netherland & Slovenia & Netherland & Slovenia & Netherland \\
\hline \multicolumn{9}{|l|}{ Subjective } \\
\hline \multicolumn{9}{|l|}{ Understanding } \\
\hline Comprehensibility & 4.92 & 4.98 & 3.27 & 4.31 & $t(153)=-7.46$ & $t(248)=-3.80$ & $p<0.001$ & $p<0.001$ \\
\hline Help to Shop & 5.00 & 4.41 & 3.37 & 2.75 & $t(153)=-7.21$ & $t(248)=-8.86$ & $p<0.001$ & $p<0.001$ \\
\hline Complexity & 3.99 & 3.59 & 2.52 & 2.43 & $t(153)=-6.07$ & $t(248)=-6.43$ & $p<0.001$ & $p<0.001$ \\
\hline Liking & 4.96 & 4.32 & 4.50 & 4.41 & $t(153)=-2.61$ & $t(248)=-4.17$ & $p=0.01$ & $p>0.05$ \\
\hline
\end{tabular}

In the following part, we report in detail the effects on each tested item.

\subsection{Subjective Understanding}

3.1.1. Comprehensibility

In Slovenia, NutrInform Battery reported a mean of 4.92, whereas the Nutri-Score registered a mean of 3.27 , showing a statistically significant difference $(\mathrm{t}(153)=-7.46$ : $p<0.001)$. Similar results were seen in the Netherlands, where NutrInform Battery obtained a mean of 4.98 vs. the 4.31 of Nutri-Score, and there was a significant overperformance $(\mathrm{t}(248)=-3.80: p<0.001)$. In both countries, NutrInform Battery performed significantly better than the Nutri-Score, confirming the results of prior research in other European countries, hence we confirm H1a and H1b.

\subsubsection{Help-to-Shop}

Starting from Slovenia, our results reported a higher performance for the NutrInform Battery compared to the Nutri-Score regarding help-to-shop $\left(\mathrm{M}_{\text {NutrInform Battery }}=5.00\right.$; $\left.\mathrm{M}_{\text {Nutri-Score }}=3.37 ; \mathrm{t}(153)=-7.21, p<0.001\right)$. Results were also confirmed in the Netherlands $\left(\mathrm{M}_{\text {NutrInform Battery }}=4.41\right.$ vs. $\mathrm{M}_{\text {Nutri-Score }}=2.75$, with $\left.\mathrm{t}(248)=-8.86, p<0.001\right)$. Also, for this dimension, NutrInform Battery outperformed Nutri-Score, confirming the results obtained in other European countries, therefore we confirmed H1c and H1d.

\subsubsection{Complexity}

The third sub-dimension of subjective understanding reported a similar performance to the previous one in both countries, and was consistent with the findings of the extant research.

In Slovenia, we reported, for the NutrInform Battery, a mean of $\mathrm{M}_{\text {NutrInform Battery }}=3.99$, higher than the one registered for the Nutri-Score label $\left(\mathrm{M}_{\text {Nutri-Score }}=2.52\right)$, with a significant difference $(t(153)=-6.07, p<0.001)$. Furthermore, in the Netherlands, we reported a similar situation in which the NutrInform Battery showed a better performance than the NutriScore $\left(\mathrm{M}_{\text {NutrInform Battery }}=3.59\right.$ vs. $\left.\mathrm{M}_{\text {Nutri-Score }}=2.43, \mathrm{t}(248)=-6.43, p<0.001\right)$, therefore, we confirmed H1e and H1f.

\subsubsection{Liking}

Regarding liking, we have registered different performances of the two labels in the tested countries. In Slovenia, the NutrInform Battery obtained a significantly better performance than the Nutri-Score $\left(\mathrm{M}_{\text {NutrInform Battery }}=4.96\right.$ vs. $\mathrm{M}_{\text {Nutri-Score }}=4.50$ with $\mathrm{t}(153)=-2.61: p=0.01)$ in terms of consumer liking, hence, we confirmed H2a. On the other hand, in the Netherlands, we did not report a significant difference between the performances of the two labels ( $\mathrm{M}_{\text {NutrInform Battery }}=4.32$ vs. $\mathrm{M}_{\text {Nutri-Score }}=4.41, \mathrm{t}(248)=-4.17$, $p>0.05)$, therefore, we rejected $\mathrm{H} 2 \mathrm{~b}$.

The results obtained in the two tested countries reported in Table 6 show a similar performance of the NutrInform Battery on comprehensibility, help to shop and complexity. 
In addition, the comparison between the two countries showed a higher mean for the NutriScore in the Slovenian population than the Dutch people, even though the Netherlands had decided to adopt it as the official label.

\section{Discussion and Conclusions}

Our work aimed at providing additional evidence to the European debate on the harmonization of front-of-pack labels across countries, by expanding the research on the effects of two different FOPLs on consumers' subjective understanding and liking in two nations with different attitudes toward FOPLs, in terms of different healthiness and socio-political context. Specifically, Slovenia has a non-mandatory Protective Food Logo, currently employed in a very small number of cases; the Netherlands, after having utilized the Dutch Choice Label for many years, recently adopted the Nutri-Score as the official FOPL for the country.

Our research explored consumers' subjective understanding and liking of nutrientspecific (NutrInform Battery) and summary labels (Nutri-Score), confirming and validating the results of previous studies [15-17] performed in eight European countries: France; Germany; Greece; Italy; Poland; Portugal; Romania; and Spain.

Our results showed a significant mean difference between the two labels on most of the dependent variables, both in Slovenia and in the Netherlands. Specifically, the NutrInform Battery registered a better performance vs. the Nutri-Score in all the three sub-dimensions of subjective understanding - comprehensibility, help-to-shop, and complexity-in both countries. On the other hand, regarding liking, we obtained two different results. Though in Slovenia, we reported a statistically higher mean from the NutrInform Battery, in the Netherlands, the mean difference between the two labels was not statistically significant.

The main contributions of our research to the current ongoing and unsolved debate on which FOPL might better support European consumers toward informed food choices, is the validation and reinforcement of previous results on the relative performance of Nutri-Score and NutrInform Battery in terms of subjective understanding and liking. This paper presents insights that can help European policy-makers define the type of FOPL to be adopted EU-wide.

Our work is not exempt from limitations; for example, more countries could be analysed in order to extend the generalization of the reported results; the study focused on subjective understanding, however, further research could test the NutrInform Battery on objective understanding as well. Furthermore, future research could explore the reason of the different performance of Nutri-Score in terms of subjective and objective understanding. Also, future streams might focus on more behavioural variables. In addition, to promote informed and balanced diets among consumers, it could be useful to test supporting tools that could compute the total of calories and nutrients taken throughout the day, to track energy and nutrients in food against the recommended daily intakes.

Author Contributions: Conceptualization, M.F.M.; Data curation, A.B.; Formal analysis, A.B.; Investigation, A.G.; Methodology, M.F.M., A.B. and A.G.; Project administration, A.B.; Software, A.B.; Supervision, M.F.M.; Validation, M.F.M., A.B. and A.G.; Writing—original draft, M.F.M., A.B. and A.G.; Writing-review \& editing, M.F.M., AB. and A.G. All authors have read and agreed to the published version of the manuscript.

Funding: This research received no external funding.

Institutional Review Board Statement: Not applicable.

Informed Consent Statement: Informed consent was obtained from all subjects involved in the study.

Conflicts of Interest: The authors declare no conflict of interest 


\section{References}

1. WHO. Obesity and Overweight; World Health Organization: Geneva, Switzerland, 2020.

2. Finkelstein, E.A.; Khavjou, O.A.; Thompson, H.; Trogdon, J.G.; Pan, L.; Sherry, B.; Dietz, W. Obesity and Severe Obesity Forecasts Through 2030. Am. J. Prev. Med. 2012, 42, 563-570. [CrossRef] [PubMed]

3. Senthilingam, M. COVID-19 has made the obesity epidemic worse, but failed to ignite enough action. BMJ $2021,372, \mathrm{n} 411$. [CrossRef]

4. WHO. Guiding Principles and Framework Manual for Front-of-Pack Labelling for Promoting Healthy Diet; World Health Organization: Geneva, Switzerland, 2019.

5. European Commission. Communication from the Commission to the European Parliament, the Council, the European Economic and Social Committee and the Committee of the Regions a Farm to Fork Strategy for a Fair, Healthy and Environmentally Friendly Food System. 2020. Available online: https:/ / eur-lex.europa.eu/legal-content/EN/TXT/?uri=CELEX:52020DC0381 (accessed on 27 October 2021).

6. European Commission. Proposal for a Revision of Regulation (EU) No 1169/2011 on the Provision of Food Information to Consumers. 2020. Available online: https:/ / ec.europa.eu/info/law/better-regulation/have-your-say/initiatives/12749-Foodlabelling-revision-of-rules-on-information-provided-to-consumers_en (accessed on 25 October 2021).

7. Grunert, K.G.; Wills, J.M. A review of European research on consumer response to nutrition information on food labels. J. Public Health 2007, 15, 385-399. [CrossRef]

8. Mazzù, M.F.; Romani, S.; Baccelloni, A.; Simonetti, E. In Search of Superiority: Exploring the Effectiveness Gap of Front-of-Pack Nutritional Labels. An Assessment of Consumer's Decision-Making Process Toward Healthier Food Choices. Food Sci. Nutr. 2021, 7, 1-5. [CrossRef]

9. Ducrot, P.; Méjean, C.; Julia, C.; Kesse-Guyot, E.; Touvier, M.; Fezeu, L.K.; Hercberg, S.; Péneau, S. Objective Understanding of Front-of-Package Nutrition Labels among Nutritionally At-Risk Individuals. Nutrients 2015, 7, 7106-7125. [CrossRef]

10. Egnell, M.; Talati, Z.; Hercberg, S.; Pettigrew, S.; Julia, C. Objective Understanding of Front-of-Package Nutrition Labels: An International Comparative Experimental Study across 12 Countries. Nutrients 2018, 10, 1542. [CrossRef] [PubMed]

11. Egnell, M.; Ducrot, P.; Touvier, M.; Allès, B.; Hercberg, S.; Kesse-Guyot, E.; Julia, C. Objective understanding of Nutri-Score Front-Of-Package nutrition label according to individual characteristics of subjects: Comparisons with other format labels. PLoS ONE 2018, 13, e0202095. [CrossRef]

12. Egnell, M.; Talati, Z.; Galan, P.; Andreeva, V.A.; Vandevijvere, S.; Gombaud, M.; Dréano-Trécant, L.; Hercberg, S.; Pettigrew, S. Objective understanding of the Nutri-score front-of-pack label by European consumers and its effect on food choices: An online experimental study. Int. J. Behav. Nutr. Phys. Act. 2020, 17, 146. [CrossRef]

13. Hafner, E.; Pravst, I. Ability of Nutri-Score to discriminate the nutritional quality of prepacked foods in Slovenia. Eur. J. Public Health 2021, 31 (Suppl. 3), 164-449. [CrossRef]

14. Van den Akker, K.; Bartelet, D.; Brouwer, L.; Luijpers, S.; Nap, T.; Havermans, R. The impact of the nutriscore on food choice: A choice experiment in a Dutch supermarket. Appetite 2022, 168, 105664. [CrossRef]

15. Mazzù, M.F.; Romani, S.; Baccelloni, A.; Simonetti, E. Effects on Consumers' Subjective Understanding and Liking of Front-Pack Nutritional Labels: A Study on Polish Consumers. Available online: https://www.petruzzieditore.it/wp-content/uploads/2021 /09/FUTURE-OF-THE-TRADITIONAL-DIETS.pdf (accessed on 27 October 2021).

16. Mazzù, M.F.; Romani, S.; Gambicorti, A. Effects on consumers' subjective understanding of a new front-of-pack nutritional label: A study on Italian consumers. Int. J. Food Sci. Nutr. 2021, 72, 357-366. [CrossRef]

17. Mazzù, M.F.; Romani, S.; Baccelloni, A.; Gambicorti, A. A cross-country experimental study on consumers' subjective understanding and liking on front-of-pack nutrition labels. Int. J. Food Sci. Nutr. 2021, 72, 833-847. [CrossRef] [PubMed]

18. Kupirovič, U.P.; Hristov, H.; Hribar, M.; Lavriša, Ž.; Pravst, I. Facilitating Consumers Choice of Healthier Foods: A Comparison of Different Front-of-Package Labelling Schemes Using Slovenian Food Supply Database. Foods 2020, 9, 399. [CrossRef] [PubMed]

19. Jewell, J. What is the Evidence on the Policy Specifications, Development Processes and Effectiveness of Existing Front-of-Pack Food Labelling Policies in the WHO European Region; WHO: Geneva, Switzerland, 2019.

20. Miklavec, K.; Pravst, I.; Raats, M.M.; Pohar, J. Front of package symbols as a tool to promote healthier food choices in Slovenia: Accompanying explanatory claim can considerably influence the consumer's preferences. Food Res. Int. 2016, 90, 235-243. [CrossRef] [PubMed]

21. Delhomme, V. Improving Food choices Through Nutrition Labelling: Towards a Common "Nutri-Score" Scheme Across the EU. College of Europe Policy Brief: 2020. Available online: https://www.researchgate.net/publication/340528705_Improving Food_Choices_Through_Nutrition_Labelling_Towards_a_Common_'Nutri-Score'_Scheme_Across_the_EU (accessed on 28 October 2021).

22. Gregori, D.; Ballali, S.; Vögele, C.; Gafare, C.E.; Stefanini, G.; Widhalm, K. Evaluating food front-of-pack labelling: A pan-European survey on consumers' attitudes toward food labelling. Int. J. Food Sci. Nutr. 2013, 65, 177-186. [CrossRef] [PubMed]

23. Gregori, D.; Ballali, S.; Vögele, C.; Galasso, F.; Widhalm, K.; Berchialla, P.; Baldi, I. What Is the Value Given by Consumers to Nutritional Label Information? Results from a Large Investigation in Europe. J. Am. Coll. Nutr. 2015, 34, 120-125. [CrossRef]

24. Global Obesity Observatory. Available online: https://data.worldobesity.org/ (accessed on 20 October 2021).

25. Van Tongeren, C.; Jansen, L. Adjustments Needed for the Use of Nutri-Score in the Netherlands: Lack of Selectivity and Conformity with Dutch Dietary Guidelines in Four Product Groups. Int. J. Nutr. Food Sci. 2020, 9, 33-42. [CrossRef] 
26. Vyth, E.L.; Steenhuis, I.; Mallant, S.F.; Mol, Z.L.; Brug, J.; Temminghoff, M.; Feunekes, G.I.; Jansen, L.; Verhagen, H.; Seidell, J.C. A Front-of-Pack Nutrition Logo: A Quantitative and Qualitative Process Evaluation in the Netherlands. J. Health Commun. 2009, 14, 631-645. [CrossRef]

27. Vyth, E.L.; Steenhuis, I.H.; A Vlot, J.; Wulp, A.; Hogenes, M.G.; Looije, D.H.; Brug, J.; Seidell, J.C. Actual use of a front-of-pack nutrition logo in the supermarket: Consumers' motives in food choice. Public Health Nutr. 2010, 13, 1882-1889. [CrossRef]

28. van Herpen, E.; Seiss, E.; van Trijp, H.C. The role of familiarity in front-of-pack label evaluation and use: A comparison between the United Kingdom and The Netherlands. Food Qual. Prefer. 2012, 26, 22-34. [CrossRef]

29. Smed, S.; Edenbrandt, A.K.; Jansen, L. The effects of voluntary front-of-pack nutrition labels on volume shares of products: The case of the Dutch Choices. Public Health Nutr. 2019, 22, 2879-2890. [CrossRef] [PubMed]

30. Egnell, M.; Talati, Z.; Gombaud, M.; Galan, P.; Hercberg, S.; Pettigrew, S.; Julia, C. Consumers' Responses to Front-of-Pack Nutrition Labelling: Results from a Sample from The Netherlands. Nutrients 2019, 11, 1817. [CrossRef]

31. Möser, A.; Hoefkens, C.; Van Camp, J.; Verbeke, W. Simplified nutrient labelling: Consumers' perceptions in Germany and Belgium. J. Consum. Prot. Food Saf. 2010, 5, 169-180. [CrossRef]

32. Allen, C.T.; Janiszewski, C.A. Assessing the role of con- tingency awareness in attitudinal con-ditioning with impli- cations for advertising research. J. Market Res. 1989, 26, 30-43. [CrossRef]

33. Vargas-Meza, J.; Jáuregui, A.; Pacheco-Miranda, S.; Contreras-Manzano, A.; Barquera, S. Front-of-pack nutritional labels: Understanding by low- and middle-income Mexican consumers. PLoS ONE 2019, 14, e0225268. [CrossRef]

34. Grunert, K.G.; Fernández-Celemín, L.; Wills, J.M.; Bonsmann, S.S.G.; Nureeva, L. Use and understanding of nutrition information on food labels in six European countries. J. Public Health 2010, 18, 261-277. [CrossRef]

35. Talati, Z.; Pettigrew, S.; Kelly, B.; Ball, K.; Dixon, H.; Shilton, T. Consumers' responses to front-of-pack labels that vary by interpretive content. Appetite 2016, 101, 205-213. [CrossRef]

36. Thiene, M.; Scarpa, R.; Longo, A.; Hutchinson, W.G. Types of front of pack food labels: Do obese consumers care? Evidence from Northern Ireland. Food Policy 2018, 80, 84-102. [CrossRef] 